\title{
A EVASÃO NO CURSO DE LICENCIATURA EM GEOGRAFIA NA UNIOESTE - CAMPUS MARECHAL CÂNDIDO RONDON/PR ENTRE OS ANOS DE 2012- 2015
}

\author{
The evasion in the course of Geography in Unioeste - Campus Marechal Cândido Rondon / PR \\ between the years of $2012-2015$
}

Marilene Francieli Wilhelm*

Marli Terezinha Szumilo Schlosser **

${ }^{*}$ Mestranda em Geografia - UNIOESTE/Francisco Beltrão - maryejaime@live.com.
** Doutora em Geografia - UNIOESTE/Francisco Beltrão - marlisch20@hotmail.com.

Recebido em 07/08/2018. Aceito para publicação em 20/08/2018.

Versão online publicada em 03/09/2018 (http://seer.ufrgs.br/paraonde)

\begin{abstract}
Resumo:
A presente pesquisa apresenta como tema a evasão no curso de licenciatura em Geografia da Universidade Estadual do Oeste do Paraná (UNIOESTE), Campus Marechal Cândido Rondon entre os anos de 2012 a 2015.0 objetivo central da proposta caracterizou-se em contextualizar e analisar a evasão no ensino superior e nas licenciaturas, de modo a desenvolver conhecimento e embasamento teórico sobre o assunto supracitado. Ainda, se desenvolveu levantamentos de dados e possíveis hipóteses da evasão, para compreender e caracterizar as dificuldades encontradas pelos discentes na conclusão do curso.
\end{abstract}

Palavras-chave: Ensino superior; evasão escolar; licenciatura em Geografia.

\begin{abstract}
:
The present research presents as evasion subject in the degree course in Geography of the State University of the West of Paraná (UNIOESTE), Campus Marechal Cândido Rondon between the years of 2012 to 2015. The central objective of the proposal was characterized in contextualizing and To analyze the evasion in higher education and in the licenciaturas, in order to develop knowledge and theoretical foundation on the subject mentioned above. In addition, data collection and possible hypothesis of evasion were developed to understand and characterize the difficulties encountered by students at the conclusion of the course.
\end{abstract}

Key-words: Higher education; School dropout; Degree in Geography

\section{Introdução}

A presente pesquisa apresenta como tema a evasão no curso de licenciatura em Geografia da Universidade Estadual do Oeste do Paraná (UNIOESTE), Campus Marechal Cândido Rondon entre os anos de 2012 a 2015. Diante da alta desistência no curso de licenciatura supracitado nos últimos anos, verificou-se que significativo percentual de acadêmicos encontram dificuldades na continuidade e término do curso. Nesse contexto, a referida pesquisa, foi desenvolvida em conjunto com o Laboratório de Pesquisa - Laboratório de Ensino de Geografia (LEG) e Linha/Grupo de Pesquisa - Ensino e Práticas de Geografia (ENGEO).

O objetivo central da proposta caracterizou-se em contextualizar e analisar a evasão no ensino 
superior e nas licenciaturas, de modo a desenvolver conhecimento e embasamento teórico sobre o assunto supracitado. Ainda, se desenvolveu levantamentos de dados e possíveis hipóteses da evasão, para compreender e caracterizar as dificuldades encontradas pelos discentes na conclusão do curso.

Apesar de a formação superior ser considerada como base para a formação profissional, inúmeros são os casos de evasão nas diversas áreas do ensino superior. Holanda (2007) aponta que os índices de evasão se caracterizam como fonte de preocupação para as Instituições de Ensino Superior (IES), sejam públicas ou privadas, por causarem prejuízos tanto para os alunos como para as IES.

De acordo com o referencial teórico consultado, a maioria das desistências dos estudantes começa a efetivar-se no decorrer do primeiro semestre e acentua-se na passagem para o segundo ano de curso. Por quê? Qual é a responsabilidade dos discentes? E qual é a responsabilidade dos docentes? Estão alunos e professores dispostos a reconhecer o problema? Estão essas partes dispostas a superar reuniões burocráticas, limitadas a formalidades, para assumir a necessidade de refletir pedagogicamente? Quando os alunos serão realmente ouvidos para tentar compreender os motivos que os levam a desistir? E, subjacentemente, por que os discentes desistem de serem professores?

Acredita-se que algum ou alguns desses fatores podem ser considerados como marco fundamental na desistência de muitos acadêmicos, visto que escolher ingressar em um curso superior pode ser uma escolha difícil, envolve decisões de âmbito pessoal e material.

A evasão discente nas licenciaturas é problema nacional, que afeta parte das Universidades do Brasil. De acordo com o Senso da Educação Superior 2013, na área educacional, foram matriculados 1.371. 767 estudantes, dos quais apenas 201. 011 concluíram o ano matriculados.

Essa defasagem, não atribuída apenas a UNIOESTE, está contribuindo para a falta de docentes em algumas áreas educacionais do ensino básico brasileiro. Embora incentivos governamentais nas licenciaturas impulsionados, como o Programa Institucional de Bolsa de Iniciação a Docência (PIBID), o índice de desistência e abandono nesses cursos são altos.

Paralelamente a isto, buscou-se a possibilidade de intervenção no foco do problema, ou seja, através da relação teoria/prática, assegurar a utilização de dados obtidos para instrumentalizar ações para amenizar/diminuir o índice de evasão no curso de licenciatura em Geografia.

Assim, não se pode perder de vista que a produção do conhecimento científico deve ser clara e transparente, acessível ao conjunto da população (GOMES, 1998). Dessa forma, a escolha do tema decorreu da necessidade de desenvolver estudos mais específicos nesta área, na tentativa de contribuir com a melhoria do curso, uma vez que as informações e dados obtidos poderão ser levados aos representantes locais da Associação de Geógrafos Brasileiros (AGB), Centro Acadêmico (CA) e repassar aos Colegiados e Centros, de modo a organizar ações concretas para diminuir a evasão.

\section{Evasão no curso de Licenciatura em Geografia: reflexão além dos números}

Ao fazer referência as evasões no Ensino Superior, nota-se que estas apresentam-se como fenômeno complexo, presente nos contextos educacionais públicos e privados. Quando se coloca em questão a evasão escolar nos cursos de Licenciatura depara-se com situação preocupante, principalmente porque o aluno evadido tem sido pouco ouvido sobre o assunto.

Com o intuito de promover o debate desta pesquisa nos diversos âmbitos, optou - se por ouvir os discentes evadidos do curso de Licenciatura em Geografia, captar suas impressões e representações sobre a Universidade, o curso que frequentou e a profissão escolhida. Nesse sentido, as reflexões acerca das evasões no referido o curso foram desenvolvidas a partir de estudos fundamentados nos retornos dos discentes evadidos entre os anos de 2012 a 2015, coletados por meio de questionários/entrevistas.

Destaca-se que a evasão escolar aqui consideradarefere-se aos casos de abandono, cancelado e cancelado por abandono. Os acadêmicos inativos e que trancaram o curso são desconsiderados na pesquisa. 
Assim, através de questionário/entrevista e análise objetivou-se: conhecer o perfil do evadido, compreender se o discente evadido desejava atuar na área que teria sido a de sua formação no curso ou pensava em outra profissão; verificar quais eram as expectativas anteriores à graduação, sobre o curso e atuação do profissional formado no curso, assim como se as mesmas eram condizentes com a realidade; analisar qual a relação entre evasão escolar e trabalho, evasão escolar com a vida pessoal; investigar quais os maiores obstáculos enfrentados pelos discentes evadidos durante o curso e o motivo principal para a evasão escolar; entender se os evadidos acreditam que algo poderia ter sido feito para evitar a evasão escolar; investigar se os evadidos voltariam ao mesmo curso e a mesma Universidade; verificar como a evasão escolar repercutiu na vida dos evadidos; analisar a comunicação entre a secretaria acadêmica, colegiado de curso e discentes evadidos; verificar a situação acadêmica atual.

Diante da análise dos dados quantitativos dos ingressantes no Curso de Licenciatura em Geografia, obtidos na Secretaria Acadêmica da UNIOESTE, a Tabela 01 apresenta o número total de ingressantes, evadidos, discentes cursando e concluintes entre os anos de 2012 a 2015 do referido curso.

Tabela 01: Curso de Licenciatura em Geografia, Unioeste - MCR: Número total de ingressantes, evadidos, cursando e concluintes (2012 - 2015)

\begin{tabular}{l|l|l|l|l|l}
\hline \hline Ano & Ingressantes & Evadidos & $\begin{array}{l}\text { Inativos/ } \\
\text { trancados/ } \\
\text { transferência } \\
\text { para outro curso }\end{array}$ & Cursando & Concluintes \\
\hline $\mathbf{2 0 1 2}$ & 37 & 19 & 01 & 09 & $2015-08$ \\
\hline $\mathbf{2 0 1 3}$ & 34 & 23 & & 11 & $2016-03$ \\
\hline $\mathbf{2 0 1 4}$ & 39 & 12 & 06 & 21 & \\
\hline $\mathbf{2 0 1 5}$ & 36 & $23^{1}$ & 02 & 11 & \\
\hline Total & 146 & 77 & & 52 & \\
\hline \hline
\end{tabular}

Fonte: Adaptado pela pesquisadora: Dados internos da IES.

Diante do exposto, observa-se que no ano de 2012, 37 discentes ingressaram no Curso, sendo que 19 discentes evadiram, 01 realizou transferência interna de curso, 09 estão cursando e 08 concluíram no ano de 2015, ou seja, 21,6\%. Em 2013 ingressaram 34 discentes, dos quais, 23 evadiram, 11 estão cursando e destes 03 irão se formar em 2017, que correspondem a 8,8\% formandos em relação aos ingressos 2013. No ano de 2014, ingressaram 39 discentes, com 13 casos de evasão, mas um voltou ao curso no ano de 2016, sendo desconsiderada a sua evasão, totalizando 12 alunos evadidos em 2014, 02 discentes inativos, 03 matrículas trancadas, 01 transferência interna de curso e 21 discentes cursando.

Para o desenvolvimento do estudo, optou-se pela pesquisa qualitativa, através da técnica de estudo de caso, com a participação de discentes evadidos do curso de licenciatura em Geografia, por meio de entrevista/questionário semiestruturado. Nesse sentido, visto que vários sujeitos da pesquisa residem em diferentes municípios do Paraná, as entrevistas/questionários foram realizadas através do e-mail, do Facebook, via Whatsapp e pessoalmente, através da gravação de áudio. Diante dos dados preliminares, entre os anos de 2012 a 2015, foi possível verificar que o número de ingressantes no curso de licenciatura em Geografia totalizou em 146 discentes (Gráfico 01).

Destes, 52 discentes, ou seja, 35\% estão cursando, 77 discentes (53\%) se evadiram do curso e 17 discentes (12\%) nomeados "outros" são considerados os discentes inativos, que trancaram o curso,

\footnotetext{
10 número de evadidos no ano de 2015 até o término das entrevistas foi de 23 discentes. Contudo, é necessário destacar que após esse período ocorreram novas evasões na turma 2015.
} 
realizaram transferência interna e estão formados (2012) .

Gráfico 01: Total de discentes ingressantes e evadidos no curso de licenciatura em Geografia-Unioeste/Marechal Cândido Rondon/PR

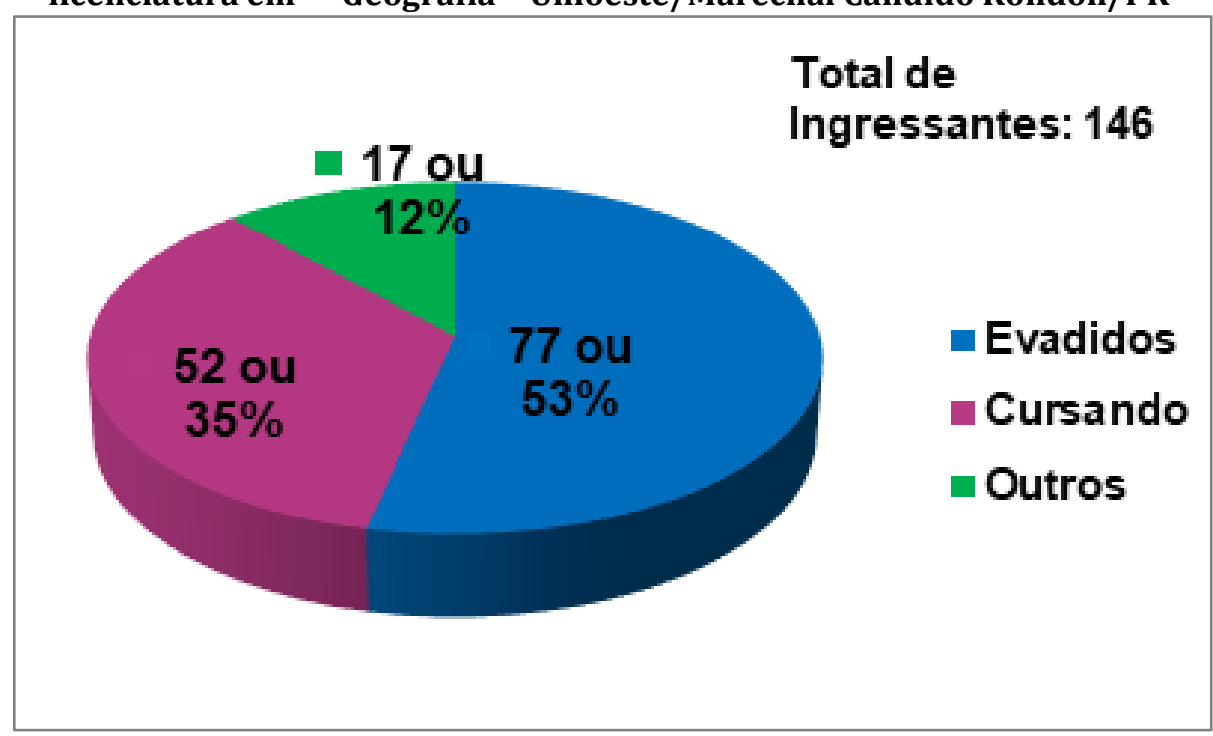

Fonte: Adaptado pela pesquisadora: Dados internos da IES.

Dos 77 evadidos, 53 colaboraram com a pesquisa. Em linhas gerais, conforme aponta o Gráfico 02, se observou diversas razões para o abandono do curso. Segundo os retornos, o principal desafio é a dificuldade de conciliar trabalho e universidade, pois $85 \%$ dos evadidos desenvolviam atividades remuneradas ao desistirem do curso.

Gráfico 02: Relação dos discentes evadidos que exerciam ou não atividade remunerada

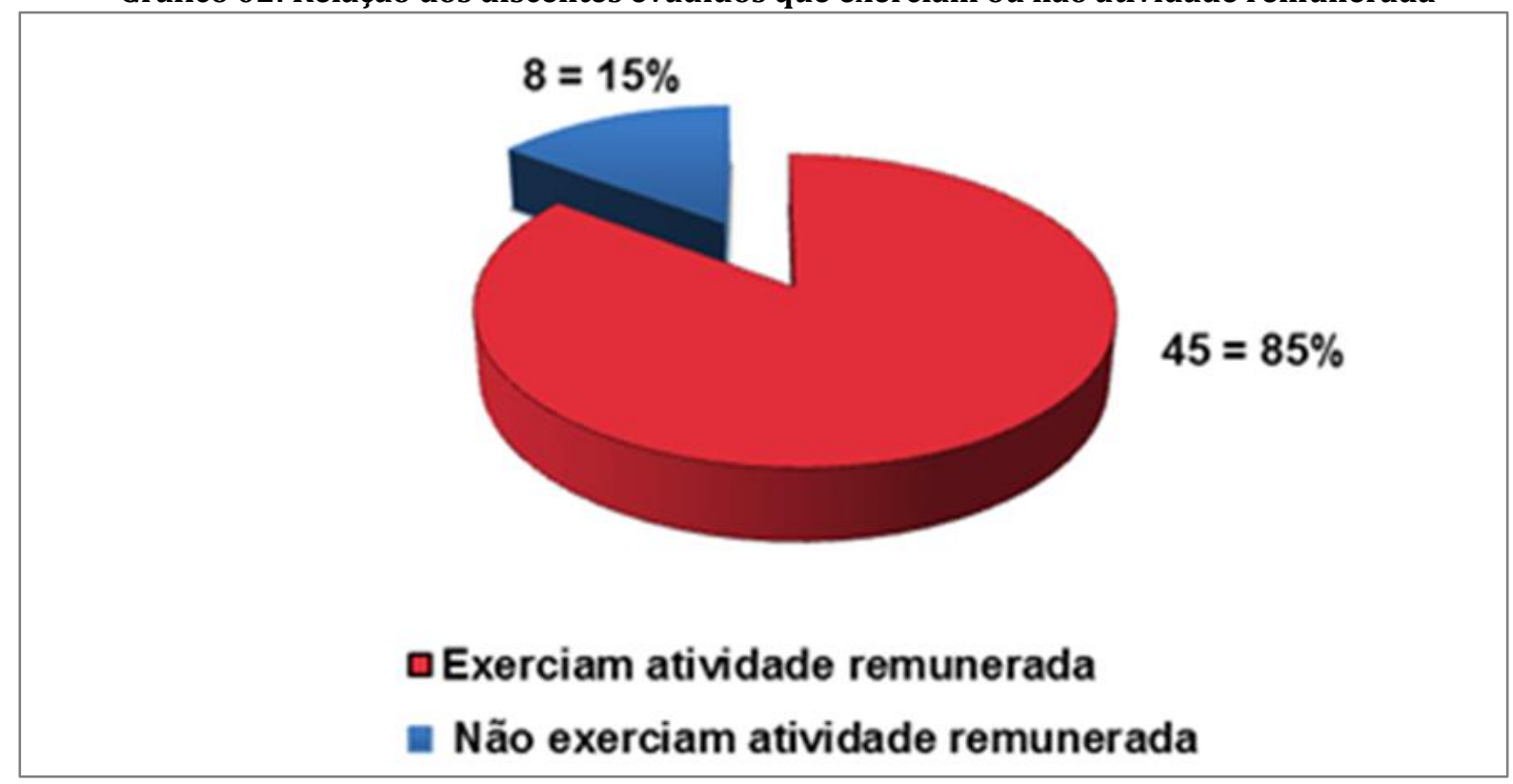

Fonte: Dados coletados pela pesquisadora em janeiro de 2017.

Seguindo esse pressuposto, constata-se que, apesar de tentar conciliar o trabalho com a universidade, parte dos estudantes trabalhadores não consegue se dedicar assiduamente ao percurso acadêmico. 
Assim, corrobora-se a ideia de Araújo (2009, p. 48), de que "[...] o trabalho parece ter invadido todos os poros da vida, ocupando parte do tempo e das preocupações do trabalhador".

Outro fator é que se verifica participação reduzida dos ex-alunos na vida interna da universidade, seja por falta de tempo, seja por falta de informações sobre seu funcionamento e espaços de atuação dos alunos na instituição.

Sobre os retornos dos evadidos entre os anos de 2012 a 2015, destaca-se o Gráfico 03, o qual apresenta que $28 \%$ dos respondes apontaram péssima ou ruim a comunicação entre Secretaria Acadêmica, Colegiado do Curso e docentes da instituição. Ainda, 27\% afirmaram não ter contato algum com a Secretaria Acadêmica, Colegiado do Curso durante o período que cursaram licenciatura em Geografia.

\section{Gráfico 03: Comunicação entre Secretaria Acadêmica, Colegiado do Curso e docentes da instituição}

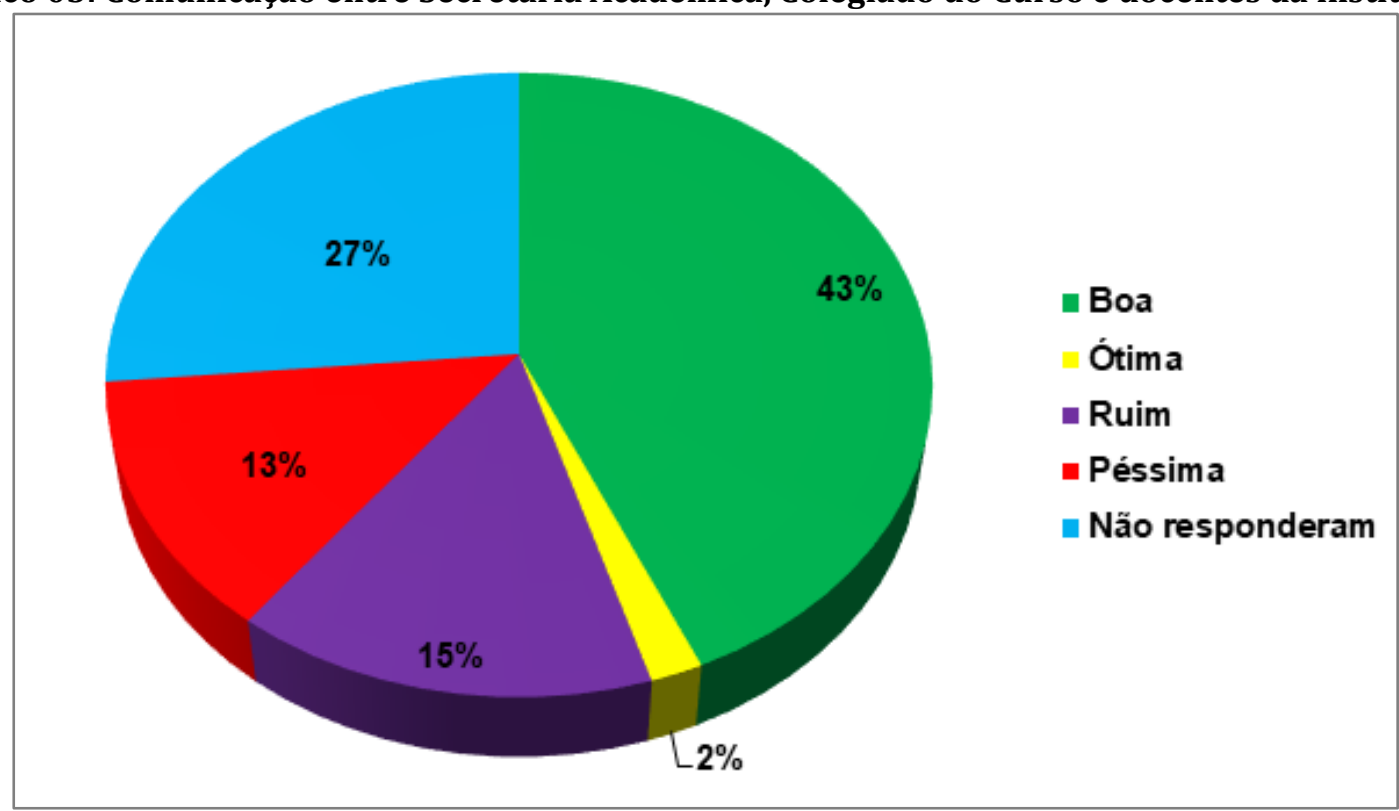

Fonte: Dados coletados pelo pesquisador em janeiro de 2017.

Em virtude dos fatos mencionados nos depoimentos, fica patente a frustração do ex-discente em não ter sido bem recebido pela Universidade, Colegiado do Curso e docentes, o que contribuiu para abreviar a sua trajetória.

Nesse contexto, aponta-se que os dados preliminares deste trabalho serão aprofundados na pesquisa de mestrado (UNIOESTE/Francisco Beltrão) que será ampliada para o curso de licenciatura em Geografia/UNIOESTE, Campus de Francisco Beltrão, entre os anos de 2010 a 2016. Assim, a propósito dos dados sistematizados com o presente trabalho, espera-se que possa servir como ponto de partida ou apoio a outras investigações com a mesma preocupação, além de desenvolver levantamentos de dados, análises dos índices e possíveis hipóteses para a evasão dos referidos cursos.

\section{Considerações Finais}

Em primeiro lugar, constatou - se que o fenômeno da evasão no curso de Licenciatura em Geografia é mais elevado do que a percepção geral que dela se tem. Levando - se em conta os dados obtidos, entre os anos de 2012 a 2015, o número total de ingressantes é de 146, dos quais, 77 ou 53\% evadiram.

Os retornos apresentados apontam impressões sobre a carreira docente, desafios e dificuldades na Universidade, perspectivas de vida após a evasão, os quais se revelam importantes elementos para a 
análise do fenômeno. Os dados são significativos, analisar e interpretar os depoimentos dos discentes evadidos permite a ampliação da compreensão do fenômeno da evasão escolar.

Em virtude do que foi mencionado no decorrer da pesquisa, sugere - se a conclusão de que variados fatores interferiram na sequência do curso de Licenciatura em Geografia. Esses aspectos tornam-se evidentes ao organizar o perfil dos discentes evadidos. 0 perfil foi desenvolvido a partir dos retornos dos respondentes, em relação a cada pergunta realizada

Nesse sentido, dos 73 discentes evadidos, 53 discentes concordaram em contribuir com a pesquisa. Em relação a variável de gênero dos discentes evadidos, $57 \%$ são do sexo masculino. Sobre a faixa etária, a maior parte dos respondentes, cerca de 57\% possuía entre 17 e 20 anos no momento da evasão. Detectou - se também que $85 \%$ dos entrevistados estudaram em Instituições Públicas no Ensino Fundamental e Médio.

Outro aspecto que chama atenção, é que 37 discentes ou $70 \%$ dos entrevistados desistiram no 1ํano de curso. E destes, 17 apresentavam idade entre 17 e 20 anos. Sobre o município residente, a maior parte, 29 evadidos morava na cidade cede do curso supracitado. Ainda, destaca - se que 83\% são solteiros. Acrescenta - se também, que $70 \%$ dos evadidos desejavam atuar na docência de Geografia.

Uma das razões mais fortes para o abandono do curso, segundo os retornos, é a dificuldade de conciliar trabalho e Universidade. Fato este que remonta $85 \%$ dos evadidos desenvolvia atividades remuneradas ao desistir do curso. Verifica-se reduzida participação dos ex-alunos na vida interna da Universidade, seja por falta de tempo, de informações sobre seu funcionamento e espaços de atuação do aluno.

Ao considerar a conciliação da vida acadêmica com a pessoal, 31 discentes afirmaram que realizavam esta, não tendo interferência na evasão. Ainda, é relevante apontar que 43 discentes afirmaram possuir fatores que contribuiriam para o impedimento da evasão. Em virtude do que foi mencionado, ressalta se que fora os fatores pessoais, possam ter ocorrido falhas na comunicação com os discentes, acrescentado ao desinteresse dos mesmos.

Sobre retornar ao curso evadido, a maior parte dos 53 respondentes, ou seja 27 discentes apontou que não voltariam ao curso de Geografia. Se voltariam a mesma Universidade, $68 \%$ afirmam o interesse em retornar a Unioeste.

A repercussão da evasão na vida dos evadidos caracterizou - se pela maioria como negativa, frustração e insatisfação em não concluir o curso. Ao indagar sobre a relação com a Secretaria Acadêmica e o Colegiado do curso, a maioria apontou como boa, estando satisfeitos com a comunicação.

Em face a situação acadêmica atual, 29 estão estudando no momento, sendo que 07 ingressaram em Universidades Estaduais ou Federais, com predomínio nos cursos técnicos e EAD. Entre as razões apontadas para ingressar em outro curso, a maior parte dos respondentes afirmaram pela proximidade Geográfica do mesmo.

De acordo com 31 evadidos, os fatores contribuintes para a evasão estão relacionados a questões individuais dos discentes (Trabalho, família, emocional, saúde, não identidade com o curso). Entretanto, é relevante apontar que 16 respondentes destacaram a influência dos fatores internos da Instituição como causas para a evasão.

Assim, a propósito dos dados sistematizados com o presente trabalho espera - se que possa servir como ponto de partida ou apoio a outras investigações com a mesma preocupação, além de auxiliar na compreensão da evasão no curso de Licenciatura em Geografia.

\section{Referências}

ADACHI, A. A. C. T. Evasão e evadidos nos cursos de graduação da UFMG. 2009. 214f. Dissertação (Mestrado em Educação) - Faculdade de Educação, Universidade Federal de Minas Gerais, Belo 
Horizonte, 2009. Disponível em: <http://www.bibliotecadigital.ufmg.br/dspace/handle/1843/HJPB7UPMBA>. Acesso em 24 de agosto de 2016.

ANDRÉ, M. Pesquisa, formação e prática docente. In: (Org.). O papel da pesquisa na formação e na prática dos professores. 11. ed. Campinas: Papirus, 2010. p. 55-69.

ARAÚJO, S. M. de; BRITI. M. A; MOTIN B. L. Sociologia: um olhar crítico. São Paulo: Contexto, 2009.

BAGGI, C. A. S; LOPES, D. A. Evasão e avaliação institucional no ensino superior: uma discussão bibliográfica. Avaliação (Campinas), Sorocaba, v. 16, n. 2, p. 355-374, jul. 2011. Disponível em: <http://www.redalyc.org/articulo.oa?id=219119106007>. Acesso em 25 de julho de 2016.

BARDAGI, M. P. Evasão e Comportamento Vocacional de Universitários: estudos sobre o desenvolvimento de carreiras na graduação. 2007. 242f. Tese (Doutorado em Psicologia) - Universidade Federal do Rio Grande do Sul, Rio Grande do Sul, 2007.

BRASIL / MEC / SESU. Secretaria de Educação Superior / Ministério da Educação. Comissão Especial de Estudos sobre a Evasão nas Universidades Públicas Brasileiras. Brasília, 1996/1997 Disponível em: <http://www.dominiopublico.gov.br/ download/texto/me001613.pdf>. Acesso em: 25 out. 2016.

CASTRO, L. P. V. Evasão dos Acadêmicos do Curso de Ciências Biológicas da Universidade Estadual do Oeste do Paraná Campus Cascavel. 2013, 162f. Dissertação (Mestrado em Educação) - Universidade Estadual do Oeste do Paraná, Cascavel, 2013.

CHAUÍ, M. A universidade pública sob nova perspectiva. Rev Brasileira de Educação, n. 27, p. 05-15, set/dez. 2003.

GADOTTI, M. Concepção Dialética da Educação e educação Brasileira Contemporânea. In: Educação $e$ Sociedade. CEDES, n. 8. São Paulo: Cortez, 1981.

GAIOSO, N. P. L. O fenômeno da evasão escolar na educação superior no Brasil. 2005. 75f. Dissertação (Mestrado em Educação) - Universidade Católica de Brasília, Brasília, 2005.

GIL, A.C. Como elaborar projetos de pesquisa. São Paulo: Atlas, 2008.

GIROTTO, E. D; MORMUL, N. M. A formação do professor de Geografia na Universidade Estadual do Oeste do Paraná - campus Francisco Beltrão: Algumas Reflexões. Revista de Estudos e Pesquisas em Ensino de Geografia. Florianópolis, v. 1, n. 1, out. 2014. Disponível em: <http://incubadora.periodicos.ufsc.br/index.php/pesquisar/article/download/3232/3800>. Acesso em 10 de março de 2016.

GOMES, A. A. Evasão e Evadidos: 0 discurso dos ex-alunos sobre evasão escolar nos cursos de licenciatura. 1998. 175 f. Tese (Doutorado em Educação) - Universidade Estadual Paulista, Marília, 1998.

HOLANDA, J. 0 desafio é ser atraente. Revista Ensino Superior. São Paulo, v.100, p. 28-32, 2007.

LAKATOS, E. M. Fundamentos de metodologia científica. São Paulo: Atlas 2003.

LOBO, M. B. C. M. et al. A evasão no ensino superior brasileiro. Cadernos de Pesquisa, [ONLINE], v. 37, n. 132, p. 641-659, set./dez. 2007.

LOBO, M. B. C. M. panorama da evasão no ensino superior brasileiro: aspectos gerais das causas e soluções. Instituto Lobo/ABMES, cadernos ํㅜ 25, 2012.

MEC/ANDIFES/ABRUEM/SESU. Diplomação, retenção e evasão nos cursos de graduação em instituições de ensino superior públicas. Revista Avaliação, Campinas, SP, no 2, p. 55-65, jul. 1996.

MEC/INEP. Educação para todos: avaliação da década. Brasília: Instituto Nacional de Estudos e Pesquisas Educacionais, 2000. Disponível em: <www.publicacoes. inep.gov.br/portal/download/174>. Acesso em: 30 jul. 2016.

MÉSZÁROS, I. A educação para além do capital. 2. ed. São Paulo: Boitempo, 2008. 
PEREIRA, F. C. B. Determinantes da evasão de alunos e os custos ocultos para as instituições de ensino superior: uma aplicação na Universidade do Extremo Sul Catarinense. 2003. 173f. Tese (Doutorado em Engenharia de Produção) - Departamento de Engenharia de Produção e Sistemas, Universidade Federal de Santa Catarina, Santa Catarina, 2003.

POLYDORO, S. A. $O$ trancamento de matrícula na trajetória acadêmica no universitário: condições de saída e de retorno à instituição. 2000. 145f. Tese (Doutorado em Educação) -Universidade Estadual de Campinas, Campinas, 2000.

PONTUSCHKA, N. N. Políticas públicas na trajetória do ensino e da formação dos professores: a construção de conhecimentos. In: ALBUQUERQUE, Maria A. M.; FERREIRA, Joseane A. S. (Orgs.). Formação, pesquisas e práticas docentes: reformas curriculares em questão. João Pessoa: Mídia, 2013, p. 433-453.

RIBEIRO, C. As causas da Evasão Universitária. ENCONTRO SETORIAL DOS CURSOS DE GRADUAÇÃO DA UNESP, 28 a 30 de junho de 1995, Águas de Lindóia (SP). Anais, São Paulo: UNESP, 1996, p. 176-190. 